\title{
Yoga as an adjunct to trauma-focused counselling for survivors of sexual violence: a qualitative study
}

Kathryn Stevens

Julia McLeod

This is an Accepted Manuscript of an article published by Taylor \& Francis in British Journal of Guidance \& Counselling on 8th May 2018, available online: wwww.tandfonline.com/10.1080/03069885.2018.1472368 
Stevens, K. \& McLeod, J. 2018. Yoga as an adjunct to trauma-focused counselling for survivors of sexual violence: a qualitative study. British Journal of Guidance and Counselling. DOI: 10.1080/03069885.2018.1472368

Yoga as an adjunct to trauma-focused counselling for survivors of sexual violence: a qualitative study

\section{Abstract}

Although evidence exists for the therapeutic effectiveness of yoga for people with a range of mental health difficulties, further research is necessary to determine its contribution to recovery from sexual violence. This study used Interpretative Phenomenological Analysis to explore the experience of a group-based Forrest yoga programme for woman recovering from experiences of sexual violence. The main themes to emerge were: the importance of being in a group; yoga as a means of facilitating personal learning and change; yoga as an on-going resource for living. These findings indicate that women recovering from rape and sexual abuse may experience yoga as a potentially valuable adjunct to counselling.

Key Words: adjunctive; counselling; Interpretative Phenomenological Analysis; pluralistic practice; sexual violence; yoga; trauma 


\section{Introduction}

Lifetime prevalence of Post-Traumatic Stress Disorder (PTSD) for women who have experienced sexual violence is estimated to be as high as 50\% (Creamer, Burgess \& McFarlane, 2001), exhibited through symptoms such as re-experiencing memories of the event, avoidance behaviour, and distressing emotional arousal/hypervigilance (American Psychiatric Association, 2013). Survivors of sexual violence have a higher likelihood of developing PTSD than survivors of other less intimate traumas, such as traffic accidents and natural disasters (Creamer \& Carty, 2006), and are likely to score higher on measures of depression, anxiety and fearfulness (Santiago, McCall-Perez, Gorcey \& Beigel, 1985). In particular, child sexual abuse (CSA) is a form of sexual violence with enhanced risk of complex trauma, through being associated with repeated, prolonged traumatic events, usually involving someone in a position of trust (Sanderson, 2013).

Studies of the effectiveness for psychotherapeutic interventions for PTSD have reported encouraging findings for trauma-focused cognitive behavioural therapy (CBT) (Ehlers, Clark, Hackmann, McManus \& Fennell, 2005), eye movement desensitization and reprocessing (EMDR) (Shapiro, 1989; Creamer \& Carty, 2006), and an attachmentinformed integrative approach (Katz, Cojucar, Douglas \& Huffman, 2014). However, reviews of research into the effectiveness of psychotherapeutic interventions for trauma resulting from sexual violence have reported success rates that are somewhat lower than those reported in therapy for other types of trauma (Taylor \& Harvey, 2009; Taylor \& Harvey, 2010; Vickerman \& Margolin, 2009). Beyond the profound psychological and emotional effects of sexual violence, there are additional factors that may limit the effectiveness of therapy for such individuals. For example, those who seek support may encounter waiting lists for specialist therapy, which have the effect of exacerbating their 
distress (Sanderson, 2012). Other barriers to recovery may include the cognitive and interpersonal avoidance strategies that survivors of sexual violence may develop in order to cope with the after-effects of trauma (Burgess \& Holmstom, 1979) and a lack of social support (Larance \& Porter, 2004).

Central themes in the lives of those who have experienced sexual violence are helplessness and loss of control after being overpowered and violated by someone threatening the life or integrity of the victim (Morrow\& Smith, 1995). Recovery typically involves the survivor taking an active role in their recovery, acknowledging the presence of barriers, and exploring different helpful ways these barriers can be overcome (Stige, Rosevinge \& Traeen ,2014). Those who have recovered report that it helpful to access multiple recovery strategies and resources in order to fully integrate diverse aspects of the traumatic event/events to which they have been exposed, and to cope effectively with the after-effects of these experiences (Grossman, Sorsoli \& Kia-Keating, 2006; Morrow \& Smith, 1995)

The present study focuses on yoga as a possible resource for survivors of sexual violence. Yoga is a physical and spiritual discipline that has been practiced for more than 5000 years. Although many schools of yoga have been developed, yoga practice typically involves breath work alongside holding specific body postures, in a group setting facilitated by a teacher (Field, 2011). Reviews by Gallegos, Crean, Pigeon and Heffner (2017) and Nolan (2016) have confirmed the effectiveness of yoga as an adjunct to psychological therapy in the treatment of trauma. Positive benefits are more likely to be sustained when the person continues to practice yoga after the end of therapy (Rhodes, Spinazzola \& van der Kolk, 2016). Studies of the use of yoga in therapy for survivors of sexual violence report that participants describe benefits in such areas as enhanced selfcompassion and mindfulness (Crews, Stolz-Newton \& Grant, 2016) and decreased body 
tension, improved quality of sleep, ability to handle intrusive thoughts and manage stress, and heightened sense of well-being (Pence, Katz, Huffman \& Cojucar, 2014).

The aim of the present study is to build on the findings of Crews, Stolz-Newton and Grant (2016), and Pence et al. (2014) by using qualitative methods to explore the meaning and experience of yoga for female survivors of sexual violence in greater depth, within a different cultural and professional setting - a Rape Crisis centre in Scotland. Over 3800 women received support from 14 Rape Crisis centres in Scotland in 2016-2017, with sexual violence, such as rape (43\%), child sexual abuse (25\%), and sexual assault (18\%), as the primary reason for seeking help. Some of the key self-reported effects of sexual violence within this client population are anxiety (72\%), depression (55\%), flashbacks (52\%), lack of confidence (49\%), sleep problems (53\%), intrusive thoughts (43\%), dissociation (21\%) and sexual problems (20\%) (Rape Crisis Scotland, 2017).

\section{Method}

\section{Research design}

At this stage of the research cycle, given the limited amount of research into yoga as an adjunct to therapy, it was valuable to describe the experience of yoga from the point of view of service users. The study is therefore exploratory in nature, intended to function as a source of insight that can be used to facilitate the design of further large-scale investigation and meaning making of this therapy modality. A qualitative approach was used to explore the meaning and lived experience of yoga for this client group. Specifically, Interpretative Phenomenological Analysis (IPA: Smith, Flowers \& Larkin, 2009) was selected as a qualitative methodology that made it possible to focus on individual differences as well as convergent themes. 


\section{Organisational context}

The participants for this study were recruited from a Rape Crisis centre that provides emotional and practical support to woman and young people who have experienced sexual violence at some point in their lives. Emotional support is primarily provided by support workers and volunteers in both a one-to-one setting and through the use of therapeutic groups. Although the job title of helpers in the centres is "support workers", they employ a range of therapeutic techniques, and are typically highly trained in counselling and psychotherapy skills and approaches. As a consequence, the term support worker and counsellor have been used interchangeably in this research. The centre offers clients up to 21 one-hour support sessions, and runs different groups, such as a transactional analysis psychoeducation group and an art group. There are also practical support services available, such as an advocacy worker for survivors going throughout the court process, a befriending service, and a "pathways" group, which aims to support the clients continue their recovery during and after the one to one support has ended. Service users can re-refer after 3 months and receive another block of 21 support sessions. The activities offered at the Centre do not comprise of a fixed programme. Instead, clients discuss with their support worker when, and if, they are ready to make use of different activities. Some participants in the present study had used the service for a number of years.

\section{Participants}

Participants were female, aged between 21-55, who had accessed support as adults following on from experiences of childhood sexual abuse, or sexual violence (usually rape) experienced as an adult. Participants in the study received on-going support from the centre and had chosen to participate in a 10 week block of Forrest Yoga classes. Some had previous experience with yoga, while others were very new to the practice. Further 
information is available in Table 1. Participants are identified by self-selected pseudonyms.

\begin{tabular}{|l|l|l|l|l|l|l|}
\cline { 2 - 7 } & $\begin{array}{l}\text { Age } \\
\text { Range }\end{array}$ & Gender & Occupation & Ethnicity & $\begin{array}{l}\text { Marital } \\
\text { Status }\end{array}$ & $\begin{array}{l}\text { Time } \\
\text { engaged with } \\
\text { support from } \\
\text { the Centre }\end{array}$ \\
\hline Alice & $35-45$ & Female & $\begin{array}{l}\text { Unable to work } \\
\text { due to disability }\end{array}$ & British & Single & $5+$ Years \\
\hline Bea & $45-55$ & Female & Unemployed & British & Married & 5+ Years \\
\hline Carol & $45-55$ & Female & $\begin{array}{l}\text { Unable to work } \\
\text { due to disability }\end{array}$ & British & $\begin{array}{l}\text { Co- } \\
\text { Habiting }\end{array}$ & Under a Year \\
\hline Dana & $35-45$ & Female & Student & Haitian & $\begin{array}{l}\text { Co- } \\
\text { Habiting }\end{array}$ & 1-3 Years \\
\hline Marcie & $21 *-25$ & Female & Student & British & Single & Under a year \\
\hline
\end{tabular}

Table 1: Participant Information $(* 21$ was minimum age for inclusion in the study)

Participants were contacted initially through the support worker at the Rape Crisis centre who had set up and organised the yoga programme and was already known to them. Potential participants were provided with written information about the study. Those who opted to take part attended a preliminary meeting with the researcher. Participants were informed they could withdraw from the study at any time up to the point of completion of analysis without having to give a reason. All clients approached by the support worker agreed to participate in the study. The interviews with the participants took place four to five months after the yoga block in question had finished, and a follow-up email was sent to participants eight months after the end of the yoga block.

\section{Intervention}

Participants had all completed a block of ten 90 -minute sessions of Forrest yoga in a yoga 
studio separate from the Rape Crisis centre. Forrest yoga has been developed to work specifically with trauma and trauma related symptoms (Forrest, 2011). Its adherents claim that Forrest yoga facilitates the ability of the traumatised person to self-regulate emotion; breath-work alongside physical postures can activate the parasympathetic nervous system, which in turn can reduce anxiety (Emerson, Sharma, Chaudhry \& Turner, 2009). Forrest yoga has developed a specific emphasis on focusing on feelings (Billard, 2011; Cook, 2009), through practices such as grounding the participant through breathing, grounding physically though the use of "active feet", and spending time working on specific areas of the body where stress is experienced in the body, such as the jaw and neck (Forrest, 2012). The yoga classes attended by Rape Crisis centre clients were not open to general members of the public and comprised small numbers of participants in an intimate setting.

\section{Data collection}

Data was collected using a semi-structured interview, and a follow-up email to participants (three months later) to enable further exploration of experiences reported in the interview. The interview guide explored: difficulties relating to the sexual violence experienced by participants, whether yoga benefitted them and how, and what their future participation with yoga would be. The researcher was as non-directive as possible during the process. Participants received a copy of the interview guide in advance of the scheduled interview session. Interviews lasted between 60-90 minutes and were audio-recorded. The follow-up email sent to participants included a brief summary of the main themes that had emerged from preliminary analysis of their interview, specific aspects of their experience around which the researcher sought further clarification, and an invitation to share any further reflections that may have occurred to them since the interview. They were requested respond in as much or as little detail as they wished. The email also included a reminder of 
contact details of sources of support if any aspect of the study had been upsetting. All participants responded positively to follow-up emails.

\section{Data analysis}

The interviews were transcribed by the researcher and subjected to Interpretative Phenomenological Analysis (Smith, Flowers, \& Larkin, 2009). This involved the researcher immersing herself in data provided by the transcript and audio recordings through repeating listening. Once the researcher had become familiarised with an interview, the transcript was annotated to identify meaning and emergent themes. This process was informed by an intention to elucidate the ways in which the experiences described by participants were meaningful or significant to their lives (Smith, Flowers, \& Larkin, 2009).

Validity procedures employed in the study included monthly meetings with a research group who read and commented on segments of the data analysis. Research participants were invited to comment on the preliminary analysis of themes derived from their interview. Formal auditing of the final analysis was carried out by two experienced qualitative researchers.

In the results section, below, when referring to frequency of reporting of specific themes by participants, the term 'all' means that all participants contributed to the theme, and 'most' means 3-4. Experiences reported by only one or two participants have not been included in the analysis.

\section{The researchers}

The primary researcher (AA) had initially completed a training placement with the specific Rape Crisis centre in which this research took place while studying counselling at the 
University of XXX, and at the time of the study was employed as a support worker with a different Rape Crisis centre in a neighbouring city. She had no prior or subsequent professional contact with any of the participants in the study. Before commencing the study, the researcher documented her preconceptions around the themes that might be generated in the study. She was aware of no specific hypothesis that she was aiming to prove. The researcher had some personal experience as a participant in yoga, and no previous experience of sexual violence. The researcher kept a research journal, in which she recorded her personal responses to interviews, and other relevant reflections. A report based on this journal was discussed with her research supervisor. BB supervised the study. She is an experienced researcher and counselling trainer, with extensive experience in working with survivors of sexual violence, and both personal and research involvement in exploring the health benefits of yoga. Before commencing the study, she assumed that yoga might be difficult for some survivors of sexual violence, because of the amount of physical contact and body awareness that it required.

\section{Ethical considerations}

The client group in this study was identified as a potential vulnerable group due to their experiences of sexual violence and on-going participation in therapy. In order to maximise participant safety, interviews took place in a Rape Crisis centre with which they were all familiar. They were recruited by a support worker who was known to them and who could assess if they were in a good enough place to engage with the research and the primary researcher had been involved with the Rape Crisis centre. All participants were made aware that the researcher would stay afterwards for a long debrief if anything came up that they wanted to talk about. Alternatively, if they were more comfortable with a different support worker there was someone else on hand to support the client. The informed 
consent procedure acknowledged that it could be upsetting for participants to discuss what brought them to seek support from the Rape Crisis centre and reasons for participating in the Forrest yoga program, and that the interview was not a support or therapy session. A further ethical consideration was that participants may have felt obliged to participate in the study out of indebtedness for the services they received and relationships with service providers - the issue of freedom to decline participation was emphasized in the informed consent process. The researcher took time before and after reflecting on the interview and sought supervision in order to remain a researcher and not slip into being a counsellor. The protocol for the study was approved by the Research Ethics Committee, School of X and Y, University of ZZ. No participants were adversely affected by their involvement in the study.

\section{Findings}

Analysis of interview transcripts and email responses made yielded five main themes, and a further set of subsidiary themes, as outlined in Table 2. A summary of the main findings of the study (description of themes and sub-themes) was sent to participants for comment. All of the participants agreed with the themes listed in Table 2 and used their replies to highlight further areas of importance to them in relation to their experience of yoga.

\section{Main theme 1. Dealing with major problems in living}

In the interviews, participants spoke at length about significant difficulties in their lives, associated with their experience of having been sexually abused, and how they believed that yoga had helped them to deal with these problems.

Sub theme 1.1. The impact of abuse 
Yoga as an adjunct to trauma-focused counselling: a qualitative study

Participants described fundamental ways in which their sense of self had been distorted by the abuse they had experienced:

'....you're told things.... that you were ugly stupid, you know all the rest of it, and normally a fist behind it as well, on top of the sexual stuff...' (Bea)

'My mind just tells me that I'm a bad person and I don't deserve help, because that's what my mum used to say to me, I was evil. Obviously at the time it was to stop me from telling anybody, but all these years later it's still there quite strong. ' (Carol)

Sub-theme 1.2. Feeling isolated and having difficulty around people

The experience of abuse had left most participants with severe difficulties in making friendships or sustaining intimate relationships. For example, Alice described these aspects of her life as 'quite an effort', and Carol acknowledged that 'I don't go out very often....I don't like have friends because I've isolated myself.'

\section{Sub-theme 1.3. A life of fear and anxiety}

All participants in the study described themselves as living in a state of heightened fear and vigilance: 'I mean obviously I knew I was scared all the time and frightened and all things, I knew it was because of what had happened to me' (Bea). Carol reported that: 'I just lived with the tension and the anxiety made you feel like that. If I knew how tense I was, I... I didn't know that could ever be released'. For most, this aspect of their lives included frequent panic attacks.

\section{Sub-theme 1.4. Dissociation}

The experience of recurrent dissociation was familiar to most informants: 
'I tend to split physically and mentally because it's just easier for me.....I'd been in contact with the Samaritans because I was suicidal and I didn't really know why. And I was talking to them one night and I was telling them what had happened. But it was like I was remembering it at the same time as telling them.' (Alice)

'I lost memory and time, where I am, even speaking with people I just switch off' (Dana)

'I was having dissociative episodes, not long ones, but I was dissociating like, if I was trying to have sex with my boyfriend and like doing other stuff that was really bothering me.' (Marcie)

\section{Sub-theme 1.5. Desire for self-understanding}

Most of the participants in the study expressed deep longings to make sense of their lifedifficulties, as a requirement for being able to move on in their lives. Alice described this desire as 'a project...to learn more and learn what it's all about'. Marcie regarded the counselling she had received as particularly valuable because it had helped her to 'understand why I feel the way I do a bit better. I feel like I've had a year of massive emotional processing...'

\section{Main theme 2. The importance of being in a group}

All of the participants in the study reported that it had been valuable to be a member of a group of women who had a shared background and who accepted and understood each other. Most of them stated that they would not have been able to attend a normal, open yoga class. In follow up questions Alice emphasised the acceptance she felt in the yoga group suggesting 'to have a sense of belonging as part of the group' (Alice-follow up email response) as an additional theme, re-emphasising the importance of the group. 
Yoga as an adjunct to trauma-focused counselling: a qualitative study

Sub-theme 2.1. Feeling understood and accepted by other members of the group

Alice emphasised the value of her of the level of acceptance that she felt in the yoga group: 'there's just acceptance that...if she's having a bad day... just... sort of say quietly "are you okay" and then not pushing it'. She contrasted this with the responses of 'normal' people: 'they can't accept that I'm just wanting to be quiet just now, or I'm thinking about something and they keep asking me questions - which isn't going to help'. Acceptance was also highlighted by Bea, who stated that she 'couldn't go into a normal yoga class ...you know the other woman and it's okay to be yourself'. The quality of interpersonal support in the yoga group was described by Dana in these words: 'we were not doing things perfect, we were supporting one another, we knew what we'd been through so... and that support, that being with the group, looking after others... really, I loved it, it really helps me.'

Sub-theme 2.2. The process of moving from isolation to inclusion in the group All of the women who were interviewed described themselves as being socially isolated. For example, Dana reflected that 'I was isolating myself from other people - I feel those panic attacks [when I'm with others]'. Being in the yoga group therefore represented a challenge, and a process of gradually coming to feel included:

'Yeah, there was more like...talking after the class as well, and talking before the class started, you know social conversations getting to know each other, and got more confident with each other.' (Alice)

The sense of being able to spend pleasurable time with others was experienced as beneficial in itself:

'It was really nice, and it just felt like...Not something that I can do normally... I've not experienced that for a long time.... I'm looking forward to the yoga starting again because it's like, a reason to go out.' (Carol) 
Yoga as an adjunct to trauma-focused counselling: a qualitative study

'It's really really good... having sort of nice relaxed social engagements helped bring up my confidence and how I felt about interacting with people and trusting them again, which was good.' (Marcie)

Sub-theme 2.3. Participation in a structured activity makes it easier to be with others The repetitive structure of the group was viewed as helpful, in relation to being with others, because it reduced the potential awkwardness of knowing what to say and how to be. Marcie summed up this sentiment in her observation that "just dumping yourself in a social situation with no structure isn't going to help'. Alice commented that 'the conversation was about the yoga...there wasn't any pressure'.

Sub-theme 2.4. The experience of safety in the group

It was very important to participants that the group was experienced as a safe place. A sense of being safe made it possible to be open to new experiences. The clearest statement of this theme came from Carol:

'....having a safe place is important; because you're letting some of yourself go when you're doing yoga, so you need to be in a safe place. Like when I come here [to the Rape Crisis centre] and speak to [name of therapist] I'm in a safe space, so I know I can let things go. ..... Yoga's exactly the same, it's like therapy.'

This passage captured a sense that was less fully articulated by other participants, around the value of being able to have a safe place in which different feelings and a different sense of self could be experienced, that was in contrast to the emotional pain that dominated much of the rest of their lives.

Main theme 3. Aspects of yoga that facilitated personal learning and change 
Yoga as an adjunct to trauma-focused counselling: a qualitative study

Participants were already engaged in a process of personal learning and change, as part of having made the decision to seek help from the Rape Crisis centre and make use of the various activities that it provided. Within this context, the yoga group was viewed as offering a set of specific opportunities for further personal development.

\section{Sub-theme 3.1. Overcoming challenge}

Participation in the yoga class allowed most members to face and overcome challenges, leading to a strengthened sense of their own capabilities: 'I think it was more challenging than I expected. Like I was expecting physically challenging.... but it was quite mentally quite difficult as well' (Alice). This was continued after the initial research as shown in the follow up questions for most participants, 'I'm enjoying [the] challenge of trying to remember positions and pushing myself a bit more physically' (Alice-follow up email response).

\section{Sub-theme 3.2. Learning to stay focused}

It was helpful to take part in an activity that required consistent focus and attention. As Alice stated: 'I felt I was totally focusing on it at that time, whereas a lot of the time in my head...things are going on'. Remaining focused 'helps a lot, because it takes your mind off whatever your mind is making you anxious about' (Carol). This aspect of yoga was not only helpful in taking attention away from rumination and worry, but because it was pleasurable in itself: 'I'm not thinking anything else, just do that, and enjoying just doing that' (Dana). Being focused could also lead to reduction in anxiety: 'I' $m$ a really tense fidgety person, so stretching out and having to stay in the same place and concentrate on you makes me focus in a different way then I usually would and sort of de-tense' (Marcie).

Sub-theme 3.3. The yoga teacher as a facilitative presence 
The yoga teachers who took the class were described as 'patient' and 'calm': 'it's like somebody's looking after you...she's not just there' (Carol). Several participants reported that they had initially been embarrassed about 'doing it wrong' but had been sensitively coached and advised by the teacher, leading to a sense of accomplishment. There was also a running theme of the teacher individualising the practice for each participant depending on their ability and comfort; she's so calm and she explained everything. And the fact she allows to do what we can, and if something doesn't work she'll find another position that might work for every one of us (Dana). At other moments, the teacher might physically intervene in a way that had a direct impact on well-being:

'it's like she got warm magic hands, they're all warm and magic and she hardly touches you, so that you know what you're doing wrong, you know, your twisting your neck slightly the wrong way, and she slightly moving your head so you're in the right position' (Carol)

Participants mentioned trying yoga at home but felt the lack of a teacher made a difference, 'I have been trying to do the yoga myself at home because of the benefits, but sadly it's not the same as having a leader' (Bea: follow up email response).

\section{Main theme 4. Changes that occurred through doing yoga}

Informants reported several different types of beneficial learning and change that occurred as a result of yoga.

Sub-theme 4.1. Learning how to use patterns of breathing to maintain well-being A highly beneficial source of learning, mentioned by all participants, related to the capacity to exert active control over breathing as a means of bringing about change in feelings. Participants reported that this aspect of yoga was difficult to learn, but had an invaluable effect: 
Yoga as an adjunct to trauma-focused counselling: a qualitative study

'...it's just like, finding that steady breath and focusing on that and learning how to control that and stuff like that. That can be really good for when I'm really anxious' (Marcie)

In the follow up data, it was clear that this was a piece of learning that continued, '[I] am using some of the breathing exercises at home-especially in terms of breathing exercises' (Alice: follow up email response).

Sub-theme 4.2 Self-acceptance and understanding For most participants, an important change to emerge from doing yoga was a gradual increase in self-acceptance: 'I just sort of realised that this is never going to go away...I've accepted me for who I am and what I am' (Bea); 'I understand that there's nothing I can do, my brain will take time to heal that. I'm more patient. More patient with myself' (Dana). This was a continued journey after the yoga had finished as well, with Alice saying she was using exercises at home to 'accept/acknowledge and let go of obsessive thoughts' (Alice-follow up email response). For some, this change reinforced a process that was already unfolding within counselling:

'One of the things I've found consistently in my counselling here is being way too hard on myself about everything all the time. So it has been good to have a bit more compassion and understanding about why stuff's the way it is.'

(Marcie)

Sub-theme 4.3 Relief from anxiety

A particularly valued outcome of yoga, for all participants, was the experience of feeling more relaxed and less anxious: 
Yoga as an adjunct to trauma-focused counselling: a qualitative study

'....normally the only night I sleep all night is after yoga so it does...you know...and it does help with certain aches and pains it really does. And it just calms you down and relaxes you it's...its... so good, it really is so good.' (Bea) 'when I feel anxious and I get the metal rods, I feel them.... It's like I feel like I've got metal rods up my arms and my legs that keep me tense. But when you get to the end of your yoga, it's like someone's taken them all away, and your arms and your legs are free, and your minds all clear and *sighs* it's just a great feeling. '(Carol)

This outcome was maintained following the group, for most participants, 'The yoga was helpful for pain and relaxation' (Bea-follow up email response)

\section{Sub-theme 4.4. Mindfulness}

Over time, practising being focused on here-and-now awareness, in the yoga class, was experienced as leading to an ability to be more aware in everyday situations:

'... you're having a panic attack I know why I'm having a panic attack. I know why I understand why, I know the reason behind it. So it, it doesn't make it as scary...would it be understand your feelings? Do you know what I mean? I think....me personally, understanding my feelings helps me because then I know... why I'm in that place, I know why...that's what helps me I think. Understanding me’ (Bea)

'I realised that [in everyday life] I'm not in the present, I'm just behaving with my ex-husband, the girls call it rubber banding, going back to the past and behaving.... Even dressing and everything as I was. I wasn't aware of that until I started to do yoga' (Dana). 
Yoga as an adjunct to trauma-focused counselling: a qualitative study

Sub-theme 4.5. Gaining relief from inner critical dialogue

All of the interviewees mentioned that they lived with a harsh inner critic, that undermined their self-confidence ('my mind just tells me that I'm a bad person and I don't deserve help, because that's what my mum used to say to me... all these years later it's still there quite strong' (Carol); 'I've got an appointment with my support worker after this and um, one of the things we've worked on if I can't say I'm proud of something, or I can't say anything positive, because the self-critic just...and that's what it's doing just now'(Alice)). Taking part in yoga made it possible to 'shut off' the inner critic, through remaining focused on here-and-now bodily experiencing such as holding a pose:

'(on talking about the yoga) So it was good to be able to be totally, completely shut it off. This...That was what I found relaxing, more than the bit at the end when my head started to come back to life.' (Alice).

'Yes I...what the name...I hit myself over things. Like "I should've done this, I should be more stronger, you know the theory, you know what's going on, why are you not able to control..." You know, being quite hard on myself. It's unconscious. That stopped from the minute I was doing the exercise, and breathe and nothing. I'm safe. It's fine where I am, with the girls I am, doing exactly the same thing. Laughing at all the things we are not able to do' (Dana).

It also allowed the person to begin to take a stronger stand against their inner critic out with yoga: '... before I would've went [imitated whimpering voice] "Yeah yeah yeah". Too scared. So now I can ...say “no”, (Bea).

Sub-theme 4.6 Developing self-control 
Yoga as an adjunct to trauma-focused counselling: a qualitative study

The discipline of yoga helped to develop a sense of being in control: 'in that moment I am just in control of what I'm doing, not thinking anything else' (Carol). This could lead to greater self-control, in difficult everyday situations:

'Circular breathing is a good thing if you're really anxious or having a panic attack or something. Being able to think your way towards that and make yourself do that, especially if you're losing control I guess. It's good to step away and be able to do that.' (Marcie)

\section{Sub-theme 4.7 Gaining relief from pain and physical tension}

Participants mentioned that they experienced significant physical tension and aches and pains, as a result of living in a state of fearful vigilance. Yoga exercises allowed welcome relief from physical pain:

'There's one that I still do, one of the stretches that I find really useful on the morning because I get like spasms in my leg and one of the stretches it just seemed to release it. So I can do that in bed and...Um...if I'm up during the night...' (Alice)

'The teacher gave me some exercises to do with my hand, and after about a month or so the pain was gone.' (Bea)

Sub-theme 4.8 Relief from dissociation achieved through a growing mind/body connection Participants reported that they experienced dissociative states, through which they coped with reminders of earlier abusive episodes by retreating into an internal reality and 'switching off' - where the 'brain is not connected to the body' (Dana). Yoga functioned as a counterbalance to this process; 
Yoga as an adjunct to trauma-focused counselling: a qualitative study

'When I get really anxious whatever's going on in my head, it's reflected in my body and when you do yoga... it just feels like you're just drift, you're so relaxed you're just drifting away, and you kind of drifted out your body and you're just watching yourself. And it's like that horrible anxious person is out there, and insides all calm and relax and, when you don't have that all the time, when you just feel it, it's an amazing feeling to be that relaxed and um...I have feel like your body is like your own, you own it now, you can do whatever you need to do....' (Carol)

'(on connecting during yoga) Yeah, and reconnecting with my body in that way I think, I've not had a dissociative thing during sex for a while now, which is ideal *laughs* cos it's just like, it's such a bummer when you're like "I want to be doing this and you want to be doing this, but I'm not here for some reason and I can't make myself be here and it's really unpleasant' (Marcie)

\section{Main theme 5. Yoga as a resource for living}

Participants described yoga as resource that they used to help them to create a more satisfying life. In particular, they regarded yoga breathing techniques as being available to them as a means of coping with stressful situations. Additionally, attendance at yoga was a source of relaxation and tranquillity. In the follow up most participants were keen to take yoga forward as a resource with Dana stating 'I do want to do more yoga, actually I am interested to try other type of Yoga's, to see if there is a difference...I am considering paying for lessons at [name of yoga studio] since they have discount for students'(Danafollow up email response). In the follow up most participants also highlighted issues they found when trying to continue their yoga practice, 'Trying to find a class that I don't feel uncomfortable in is hard, I get anxious a lot.' (Marcie: follow up email response). 
Yoga as an adjunct to trauma-focused counselling: a qualitative study

Sub-theme 5.1 Yoga as a unique resource

All participants compared yoga to other resources that they had acquired through the support of the Rape Crisis centre, such as meditation, massage and art-making. Yoga was regarded as a unique resource, which offered strategies that were not available through other means. For example, Dana stated that:

I did meditation as well, by myself, not through [the Rape Crisis centre]. I know how to do mindfulness meditation, its fine, it makes sense. But when the situation happens it doesn't work. I knew all that, but mixing the breathing and moving, doing something I think makes things more...fluid....not fluid...automatic.

Yoga was perceived as unreservedly positive: 'it's all been a huge big positive. And it's so unlike life. Because there's always negative. But it was all positives. Which is just great'. (Carol)

Sub-theme 5.2 The Rape Crisis centre as a whole as a life-saving resource As a resource for living, yoga was perceived as part of a wider network of support provided by the Rape Crisis centre. As Carol testified:

I really am so grateful for having [name of support worker] and the counselling service, and I feel like they sort of saved my life because I was really on the edge. [In contrast], the mental health team, they couldn't give me enough drugs to make any difference. So... I'm on lithium and a couple of other anti-depressants and diazepam and stuff, and it only keeps a lid on it, it doesn't...what's the word...doesn't do what my counsellor can do, just talking about things and having an explanation about why things happen and the way they happen.' 
This resource was further expanded on in the follow up letter sent to participants, with Carol identifying that 'The only unhelpful thing about yoga is I could not attend a regular class without [The Rape Crisis Centre]' (Carol-follow up email response)

\section{Sub-theme 5.3 Making progress}

The impact of the yoga class as a resource for living was evaluated in terms of the extent to which the participant had a sense of making progress in the direction of a life that was free from anxiety, panic, flashbacks, dissociation and social withdrawal. For example, Alice stated that 'I set up little goals for myself' in relation to yoga, and Bea observed that 'you sort of see yourself progress a bit'. Most participants in the follow up emails described areas of personal progression that had taken place since the interviews, such as Alice, who had 'decided to try and attend a mainstream class (which is run by the same instructor)' (Alice: follow up email response).

\section{Discussion}

This study explored the experiences of women users of a Rape Crisis centre, in terms of what they took from participation in a Forrest yoga programme. Participants talked at length about how they experienced a wide range of personal and relationship difficulties arising from their exposure to sexual violence. They reported that the opportunity to engage in yoga in the context of a safe, closed group was important in enabling them to overcome barriers to participation in social situations as a whole. All participants described ways in which yoga enabled meaningful and significant personal learning and change to occur, and all of them regarded yoga as a useful resource in their process of recovery and establishing a more satisfactory life. Although there were minor differences in emphasis between participants, they all described each of the main themes to greater or lesser degrees. 
Participants in this study identified a number of life difficulties and acknowledged that the abuse had impacted significantly on their life and sense of self, resulting in most participants feeling isolated and experiencing high levels of anxiety. Their descriptions of living with the aftermath of trauma are consistent with previous research (Santiago, McCall-Perez, Gorcey \& Beigel, 1985) and diagnostic criteria (American Psychiatric Association, 2013). Anxiety was the most highly reported effect of survivors of sexual violence in Scottish Rape Crisis centres between 2016-2017, with 72\% survivors reporting anxiety as an effect of the abuse (Rape Crisis Scotland, 2017). Most participants also reported episodes of dissociation, which was characterised by losses of time and memory and experiencing a split in mind body integration in stressful or triggering situations; such as during sex or in the time after the trauma in order to cope with life. Dissociation is characteristic of individuals who have experiences of trauma (Sanderson, 2013), and fits in as one of the avoidance symptoms laid out in the DSM V (American Psychiatric Association, 2013). It would appear, therefore, that the present study was able to recruit a reasonably representative sample of this client population

A major theme in this research was the importance of being in a group, and feeling understood and accepted within this group. This was something that all participants reported to greater or lesser degrees. The feeling of being accepted was regarded as an aspect of the specific setting within which the yoga classes were conducted, with all participants expressing that it would have been harder, or even impossible, for them to have attended a 'normal' yoga group. The structure provided by yoga, the sense of safety associated with the group setting, and the importance of the yoga teacher as a facilitative presence, are consistent with Herman's (1992) model of trauma recovery, in respect of the importance of the therapeutic relationship. 
It seemed clear that it was important for participants to feel a sense of agency in relation to their process of learning. This was accomplished by the teacher tailoring yoga for each individual, correcting errors in posture in a caring manner and being a witness and ally with them through the yoga process. Another aspect of the yoga process that facilitated change was the feeling of being challenged, sometimes in unexpected ways. What appeared to be helpful here was being able to overcome challenge through experiencing a recurring process of challenge and progress that allowed participants to push their comfort zones in a safe manner. This growing sense of agency has been found to be extremely beneficial in people recovering from trauma (Stige, Rosenvinge \& Traeen, 2014) and facilitates a feeling of action towards recovery, which can be an effective counter to emotional, cognitive and interpersonal avoidance strategies arising from sexual trauma (Burgess \& Holmstrom, 1979). One of the cognitive challenges that participants experience was staying actively focused. PTSD symptoms are characterised by an inability to stay focused and present, due to hypervigilance in respect of future dangers that may occur (American Psychiatric Association, 2013). Participants in the present study described yoga practice as enabling them to stay present and focussed thereby allowing them to "take a break" from the continual whirring of anxiety and just be focused in the present. This finding confirms the conclusions of Crews, Stolz-Newton \& Grant (2016) that yoga has the potential to promote mindfulness as a therapeutic skill.

A further key finding from this research was that participants described yoga as facilitated change and learning through the use of breath work, for example through developing enhanced control and awareness of their breathing. Yoga breathing has been found to be a beneficial strategy in building up control and awareness over physical and mental states in therapeutic settings (Somerstein, 2010). Altered breathing is an established technique for regaining control over symptoms such as anxiety (Sanderson, 2012). 
Participants believed that yoga classes provided them with relief from anxiety, better sleep, relief from panic attacks, and decreased physical tension. Through the yoga block all participants also reported having a higher level of mindfulness. This extended into their life outside of yoga, such as when having a panic attack, which helped to gain control over anxiety responses. Yoga was an area where all participants reported having a sense of control over themselves, in contrast to the loss of control associated with heightened levels of generalised anxiety reported by participants. These were benefits are extremely important with regards to the literature, with most survivors engaged with Rape Crisis centres experiencing symptoms of anxiety and sleep problems (Rape Crisis Scotland, 2015). A further change through yoga was a break from inner criticism, and this break during yoga from being told they are not 'good enough' was reported as a significant moment to all participants. Alongside this was a growing level of self- acceptance, allowing for more patience with and understanding of themselves. This fits in with the literature on how yoga can help be a useful resource in building self-esteem (Benson, et al., 1994) and self-compassion (Crews, Stolz-Newton \& Grant, 2016). in survivors of sexual violence. Overall, yoga was experienced by participants as having a positive impact on well-being.

Participants reported that they came to regard yoga as a resource for living that they could carry forward into their lives. In their interviews, participants compared yoga with other helpful resources that they had used, such as individual counselling, art groups and psychoeducation groups. All participants were in agreement that they had experienced yoga as a unique resource in their lives: there was something that they got from yoga that they had not been able to achieve in any other way.

Participants in the study experienced the beneficial effect of yoga as inextricably linked to the context in which it was provided, in particular the overall support that 
participants had received from Rape Crisis - a service that all participants described as life changing or even lifesaving. Rape Crisis was viewed by all of them as a particularly valuable resource in comparison to other mental health support previously received, medication and other counselling services. This finding suggests the importance of access to professionals who are experienced and trained in working with sexual trauma. Many participants, in follow-up emails, described that they had found it hard to continue their yoga practice outside of the highly supportive environment provided by the classes organised by the Rape Crisis centre.

The evidence presented in the present study suggests that yoga may be beneficial, as an adjunct to counselling, for women who have experience sexual violence, and supports a general position that recovery may be facilitated by the adoption of an integrative or pluralistic therapeutic approach based on tailoring the therapy to the symptoms, preferences and experiences of individual service users (Cooper \& Dryden, 2016; Taylor \& Harvey, 2010).

It is important to acknowledge the limitations of this study. It was carried out on a small number of female participants from a very specific client group, any attempt to generalise from these results must be treated with caution. Informants were asked to participate in the research through a support worker already known to them. This factor may have influenced participants in the direction of giving a more positive account of their experience in the yoga group. This being said, during interviews, participants appeared engaged and honest about the process, and described detailed, concrete ways in which yoga had been helpful for them. As the interviews were between 60-90 minutes, it is unlikely that participants could consistently sustain a false impression throughout that period. Participants provided written feedback after their interviews, to confirm the themes identified through data analysis. In addition, interpretation of the data was systematically 
audited by two independent experienced researchers. Participants in this study were recruited following completion of the yoga intervention. Data was not obtained from service users who did not complete the yoga intervention. This is important as the participants that were recruited may have chosen to take part as they have a positive experience leading to them staying for the whole block and being more open to sharing their experience. It is important for future research to collect information about the experiences of participants who have not found yoga helpful.

A significant methodological issue arising in the present study is the characterisation of participants as survivors of sexual violence. While this term accurately described all of the women in the study, and the therapeutic setting within which they were receiving help, some of them had also been subjected to physical violence, domestic abuse and/or emotional abuse, and were depressed, anxious or had psychosomatic complaints. In this respect, the study reflects one of the key contemporary challenges in counselling and psychotherapy research, around whether to focus on clients with single diagnoses, or to adopt an approach that reflects routine practice.

Further research might usefully explore the themes presented in this investigation within a larger scale study, to examine their relevance to various sub-groups of clients, for example those at different stages of recovery or different time periods over which the abuse occurred (i.e. such as chronic trauma). It could also be useful to recruit participants at the start of a yoga block and see how they progressed through to the end, and at followup, using symptom measures as well as qualitative reports. From the perspective of service delivery, it would be valuable to explore the effectiveness of different ways in which specialist trauma agencies might incorporate yoga into treatment programmes. Given the evidence that the long-term benefits of yoga are associated with continuing yoga practice (Rhodes, Spinazzola \& van der Kolk, 2016), it would be valuable for future research to 
Yoga as an adjunct to trauma-focused counselling: a qualitative study

examine the factors that either facilitated or impeded the transition from a trauma-sensitive yoga classes to engagement with routine yoga sessions in groups open to the public.

\section{References}


American Psychiatric Association. (2013). Diagnostic and statistical manual of mental disorders: DSM-5. Washington, D.C: American Psychiatric Association.

Barnes, V. A., Treiber, F. A., \& Davis, H. (2001). Impact of transcendental meditation on cardiovascular function at rest and during acute stress in adolescents with high normal blood pressure. Journal of Psychosomatic Research , 51 (4), 597-605. doi:10.1016/S00223999(01)00261-6

Barnes, V., Bauza, L. B., \& Treiber, F. A. (2003). Impact of stress reduction on negative school behaviour in adolescents. Health and Quality of Life Outcomes , 1 (10), 1-7. doi:10.1186/1477-7525-1-10

Benson, H., Kornhaber, A., Kornhaber, C., LeChanu, M. N., Zuttermeister, P., Myers, P., et al. (1994). Increases in positive psychological characteristics with a new relaxationresponse curriculum in high school students. Journal of Research and Development in Education , 27 (4), 226-231.

Bergen, R. K. (2006, February). Marital rape: New research and directions. Retrieved March 20th, 2016 from VAWnet:

http://new.vawnet.org/Assoc_Files_VAWnet/AR_MaritalRapeRevised.pdf

Billard, M. (2011, July 29). Yoga guardians on a healing mission. Retrieved March 2016, 21 from The New York Times: http://www.nytimes.com/2011/07/31/nyregion/in-forrestyoga-guardians-of-a-mission-to-heal.html?_r=0

Blore, D. (2011). An interpretative phenomenological analysis (IPA) investigation of positive psychological change (PPC), including post traumatic growth (PTG).

(Unpublished Thesis), University of Birmingham, United Kingdom.

Bradlet, R., Greene, J., Russ, E., Dutra, L., \& Westen, D. (2005). A multidimensional meta-analysis of psychotherapy for PTSD. The American Journal of Psychiatry, 162 (2), 214-27. doi:10.1176/appi.ajp.162.2.214

Brown, B. (2011, January 3). Brene Brown: The Power of Vulnerability [Video file]. Retrieved May 2016 from https://www.youtube.com/watch?v=iCvmsMzlF7o

Burgess, L. A. W., \& Holmstrom, L. L. (1979). Rape: Disruption and recovery. American Journal of Orthopsychiatry , 49 (4), 648-657. doi:10.1111/j.1939-0025.1979.tb02650.x

Butler, L., Waelde, L. C., Hastings, A. T., Chen, X., Symons, B., Marshall, J., et al. (2008). Meditation with yoga, group therapy with hypnosis, and psychoeducation for longterm depressed mood: A randomized pilot trial. Journal of Clinical Psychology, 64 (7), 806-820. doi:10.1002/jclp.20496

Cantón-Cortés, D., Cortés, M., \& Cantón, J. (2012). The role of traumagenic dynamics on the psychological adjustment of survivors of child sexual abuse. European Journal of Developmental Psychology, 11 (4), 505-530. doi:10.1080/17405629.2012.660789 
Chapman, P. (2010). Learning to stand on your head: How yoga demonstrates the psychosomatic value of perspective, flexibility and strength. Psychodynamic practice, 16 (3), 305-312. doi:10.1080/14753634.2010.492144

Clark, C. J., Lewis-Dmello, A., Anders, D., Parsons, A., Nguyen-Feng, V., Henn, L., \& Emerson, D. (2014). Trauma-sensitive yoga as an adjunct mental health treatment in group therapy for survivors of domestic violence: A feasibility study. Complementary Therapies in Clinical Practice, 20, 152-158. doi:10.1016/j.ctcp.2014.04.003

Cook, L. (2009, February 15). Forrest yoga challenges with added intensity. Retrieved March 20, 2016 from Houston Chronicle: http://www.chron.com/life/article/Forrest-yogachallenges-with-added-intensity-1744808.php

Creamer, M. C., Burgess, P., \& McFarlane, A. C. (2001). Post-traumatic stress disorder: Findings from the Australian national survey of mental health and well-being. Psychological Medicine , 31 (7), 1237-1247. doi:10.1017/S0033291701004287

Creamer, M., \& Carty, J. (2006). Post-traumatic stress disorder. In A. Carr, \& M. McNulty (Eds.), The handbook of adult clinical psychology (pp. 423-557). London: Routledge.

Crews, D.A., Stolz-Newton, M. \& Grant, N.S. (2016). The use of yoga to build selfcompassion as a healing method for survivors of sexual violence. Journal of Religion \& Spirituality in Social Work: Social Thought, 35, 139-156. doi:

10.1080/15426432.2015.1067583

Curran, L. A. (2013). 101 trauma informed interventions. Eau Claire: PESI Publishing and Media.

Dass-Brailsford, P. (2007). A practical approach to trauma: Empowering interventions. New York: Sage.

Dilthey, W. (1976). Selective writings. (Rickman, Ed., \& Rickman, Trans.) Cambridge: Cambridge University Press.

Douglass, B. G., \& Moustakas, C. (1985). Heuristic inquiry: The internal search to know. Journal of Humaistic Psychology , 25 (3), 39-55. doi:10.1177/0022167885253004

Echevarria, S., Franzblau, S., Smith, M., \& Van Cantfort, T. (2008). A preliminary investigation of the effects of giving testimony and learning yogic breathing techniques on battered women's feelings of depression. Journal of Interpersonal Violence, 23, 18001808. doi:10.1177/0886260508314329

Ehlers, A., Clark, D., Hackmann, A., McManus, F., \& Fennell, M. (2005). Cognitive therapy for post-traumatic stress disorder: Development and evaluation. Behaviour Research and Therapy , 43 (4), 413-431. doi:10.1016/j.brat.2004.03.006

Ellis, C. (2004). The ethnographic I: A methodological novel about autoethnography. Walnut Creek, CA: AltaMira Press. 
Ellis, C., \& Bochner, A. P. (2006). Analyzing analytic autoethnography: An autopsy. Journal of Contemporary Ethnography , 35 (4), 429-49. doi:10.1177/0891241606286979

Ellis, C., \& Bochner, A. P. (2000). Autoethnography, personal narritive, relexivity: Researcher as subject. In N. K. Denzin, \& Y. S. Lincoln (Eds.), Handbook of qualitative research (2nd ed., pp. 733-68). Thousand Oaks, CA: Sage Publications.

Emerson, D., Sharma, R., Chaudhry, S., \& Turner, J. (2009). Trauma-sensitive yoga: Principles, practice and research. International Journal of Yoga Therapy , 19 (1), 123-128. doi:10.17761/ijyt.19.1.h6476p8084122160

Field, T. (2011). Yoga clinical research review. Complementary Therapies in Clinical Practice , 17 (1), 1-8. doi:10.1016/j.ctcp.2010.09.007

Finkelhor, D., \& Browne, A. (1985). The traumatic impact of child sexual abuse: A conceptualisation. American Journal of Orthopsychiatry, 55 (4), 530-541. doi:10.1111/j.1939-0025.1985.tb02703.x

Forrest, A. (2012). Choosing healing is the ultimate warrior action. Origin Magazine , 2223.

Forrest, A. (2011). Fierce medicine: Breakthrough practices to heal the body and ignite the spirt. San Francisco: HarperOne.

Friedrich, W. N., Leuche, M. J., Belike, R. L., \& Place, V. (1992). Psychotherapeutic outcome of sexually abused boys. Journal of Interpersonal Violence , 7, 47-57.

Gallegos, A. M., Crean, H. F., Pigeon, W. R., \& Heffner, K. L. (2017). Meditation and yoga for posttraumatic stress disorder: A meta-analytic review of randomized controlled trials. Clinical Psychology Review, 58, 115-124. doi:10.1016/j.cpr.2017.10.004

Gray, D., \& Watt, P. (2013). Giving victims a voice. London: Metropolitan Police.

Greenburg, N., Brooks, S., \& Dunn, R. (2015). Latest developments in post-traumatic stress disorder: Diagnosis and treatment. British Medical Bulletin Advance Access , 114 (1), 147-155. doi:10.1093/bmb/ldv014

Grossman, F. K., Sorsoli, L., \& Kia-Keating, M. (2006). A gale force wind: meaning making by male survivors of childhood sexual abuse. American Journal of Orthopsychiatry, 76, 434-443. doi:10.1037/0002-9432.76.4.43.

Herman, J. L. (1992). Complex PTSD: A syndrome in survivors of prolonged and repeated trauma. Journal of Traumatic Stress , 5 (3), 377-392.

Herman, J. L. (1997). Trauma and recovery. New York: Basic Books.

Herman, J. (1997). Trauma and Recovery. New York: Basic Books. 
Kirkwood, G., Rampes, H., Tuffrey, V., Richardson, J., \& Pilkington, K. (2005). Yoga for anxiety: A systematic review of the research literature. British Journal of Sports Medicine, 39 (12), 884-891. doi:10.1136/bjsm.2005.018069

Larance, L. Y., \& Porter, M. L. (2004). Observations from practice: Support group membership as a process of social capital formation among female survivors of domestic violence. Journal of Interpersonal Violence , 19 (6), 676-690.

doi:10.1177/0886260504263875

Makhija, N. J. (2014). The relationship between traumagenic dynamic responses towards childhood sexual abuse, ethnic identity, social support, trauma severity, and attitudes towards interpersonal relationships in adolescent females. (Unpublished $\mathrm{PhD}$ Thesis) Seton Hall, New Jersey.

McLeod, J. (1999). Practitioner research in counselling. (C. Feltham, Ed.) London: SAGE.

McLeod, J. (2011). Qualitative research in counselling and psychotherapy. London: SAGE.

Morrow, S. L., \& Smith, M. (1995). Constructions of survival and coping by woman who have survived childhood sexual abuse. Journal of Counselling Psychology , 42 (1), 24-33. doi:10.1037/0022-0167.42.1.24

National Health Service. (2015, September 6). Retrieved October 13, 2015 from http://www.nhs.uk/Conditions/Post-traumatic-stress-disorder/Pages/Causes.aspx

National Health Service. (2007). Adult psychiatric morbidity in England, 2007. Results of a household survey. National Health Service. Leeds: The NHS Information Centre for health and social care.

Nebraska Department of Veterans Affairs. (2007). ptsd. Retrieved March 16, 2016 from Post-traumatic stress disorder: http://www.ptsd.ne.gov/what-is-ptsd.html

Nolan, C.R. (2016). Bending without breaking: A narrative review of trauma-sensitive yoga for women with PTSD.Complementary Therapies in Clinical Practice, 24, 32-40. doi:10.1016/j.ctcp.2016.05.006

Pace, S. (2012). Writing the self into research: Using grounded theory analytic stratagies in autoethnography. (N. McLoughlin, \& D. L. Brien, Eds.) TEXT Special Issue: Creativity: Cognitive, Social and Cultural Perspectives , 13, 1-15.

Pence, P., Katz, L., Huffman, C., \& Cojucar, G. (2014). Delivering integrative restorationyoga nidra meditation (iRest $\left.{ }^{\circledR}\right)$ to women with sexual trauma at a veteran's medical center: a pilot study. International Journal of Yoga Therapy, 24, 53-62.

doi:10.17761/ijyt.24.1.u7747w56066vq78u 
Pilkington, K., Kirkwood, G., Rampes, H., \& Richardson, J. (2005). Yoga for depression: The research evidence. Journal of Affective Disorders , 89 (1-3), 13-24. doi:10.1016/j.jad.2005.08.013

Rape Crisis Scotland. (2017). Annual report 2016-17. From https://www.rapecrisisscotland.org.uk/publications/?cat=1

Rhodes, A., Spinazzola, J., \& van der Kolk, B. (2016). Yoga for adult women with chronic PTSD: A long-term follow-up study. Journal of Alternative and Complementary Medicine, 22, 189-196. doi:10.1089/acm.2014.04.07.

Sanderson, C. (2013). Counselling skills for working with trauma. London: Jessica Kingsley Publishers.

Sanderson, C. (2010). Managing sexually harmful behaviour in young children. Protecting Children Update , 68, May.

Sanderson, C. (2012). Working with survivors of rape and domestic violence. In C.

Sanderson, \& C. F. Horton (Ed.), Sage handbook of counselling and psychotherapy (3 ed.). London, UK: SAGE.

Santiago, J. M., McCall-Perez, F., Gorcey, M., \& Beigel, A. (1985). Long-term psychological effects of rape in 35 rape victims. American Journal of Psychiatry, 142 (11), 1338-1340. doi:10.1176/ajp.142.11.1338

Shapiro, F. (1989). Eye movement desensitization: A new treatment for post-traumatic stress disorder. Journal of Behavior Therapy and Experimental Psychiatry, 20 (3), 211217. doi:10.1016/0005-7916(89)90025-6

Smith, J., Flowers, P., \& Larkin, M. (2009). Interpretative phenomenological analysis: Theory, method and research. London: SAGE.

Somerstein, L. (2010). Together in a room to alleviate anxiety: Yoga breathing and psychotherapy. Procedia Social and Behavioural Science , 5 (1), 267-271. doi:10.1016/j.sbspro.2010.07.086

Stige, S. H., Rosenvinge, J. H., \& Traeen, B. (2014). A meaningful struggle: Trauma clients' experiences with an inclusive stabilization group approach. Psychotherapy Research , 23 (4), 419-429. doi:10.1080/10503307.2013.778437

Taylor, J. E., \& Harvey, S. T. (2009). Effects of psychotherapy with people who have been sexually assaulted: A meta-analysis. Aggression and Violent Behavior , 14 (5), 273-285. doi:10.1016/j.avb.2009.03.006

Taylor, J., \& Harvey, S. T. (2010). A meta-analysis of the effects of psychotherapy with adults sexually abused in childhood. Clinical Psychology Review , 30 (5), 749-767. doi:10.1016/j.cpr.2010.05.008 
Tjaden, P., Thoennes, N., Samuels, J. E., \& Thacker, S. B. (2000). Extent, nature and consequences of intimate partner violence. Washington: National Institute of Justice.

van der Kolk, B. A., Stone, L., West, J., Rhodes, A., Emerson, D., Suvak, M., \& Spinazzola, J. (2014). Yoga as an adjunctive treatment for posttraumatic stress disorder: A randomized controlled trial. Journal of Clinical Psychiatry, 75(6), e559-e565.

doi:10.4088/JCP.13m08561

Vickerman, K. A., \& Margolin, G. (2009). Rape treatment outcome research: Empirical findings and state of the literature. Clinical Psychology Review, 29 (5), 431-448.

doi:10.1016/j.cpr.2009.04.004

Wall, S. (2006). An autoethnography on learning about autoethnography. International Journal Qualitive Methods , 5 (2), 146-160. doi:10.1177/160940690600500205

Williams, M., McManus, F., Muse, K., \& Williams, J. M. (2011). Mindfulness-based cognitive therapy for severe health anxiety (hypochondriasis): An interpretative phenomenological analysis of patients experiences. British Journal of Clinical Psychology , 50 (4), 379-397. doi:10.1111/j.2044-8260.2010.02000.x

Yoga Point. (2013). Pranayama (from hatha yoga and ashtanga yoga). Retrieved March 20, 2016 from Yoga Point: www.yogapoint.com/info/pranayama.htm

\begin{tabular}{|c|c|c|c|c|c|c|}
\hline Main Theme & Sub Theme & Alice & Bea & Carol & Dana & Marcie \\
\hline $\begin{array}{l}\text { Dealing with } \\
\text { major problems }\end{array}$ & The impact of abuse & $\mathrm{X}$ & $\mathrm{X}$ & $\mathrm{X}$ & $\mathrm{X}$ & $\mathrm{X}$ \\
\hline in living & Feeling isolated and having & $\mathrm{X}$ & & $\mathrm{X}$ & $\mathrm{X}$ & $\mathrm{X}$ \\
\hline
\end{tabular}




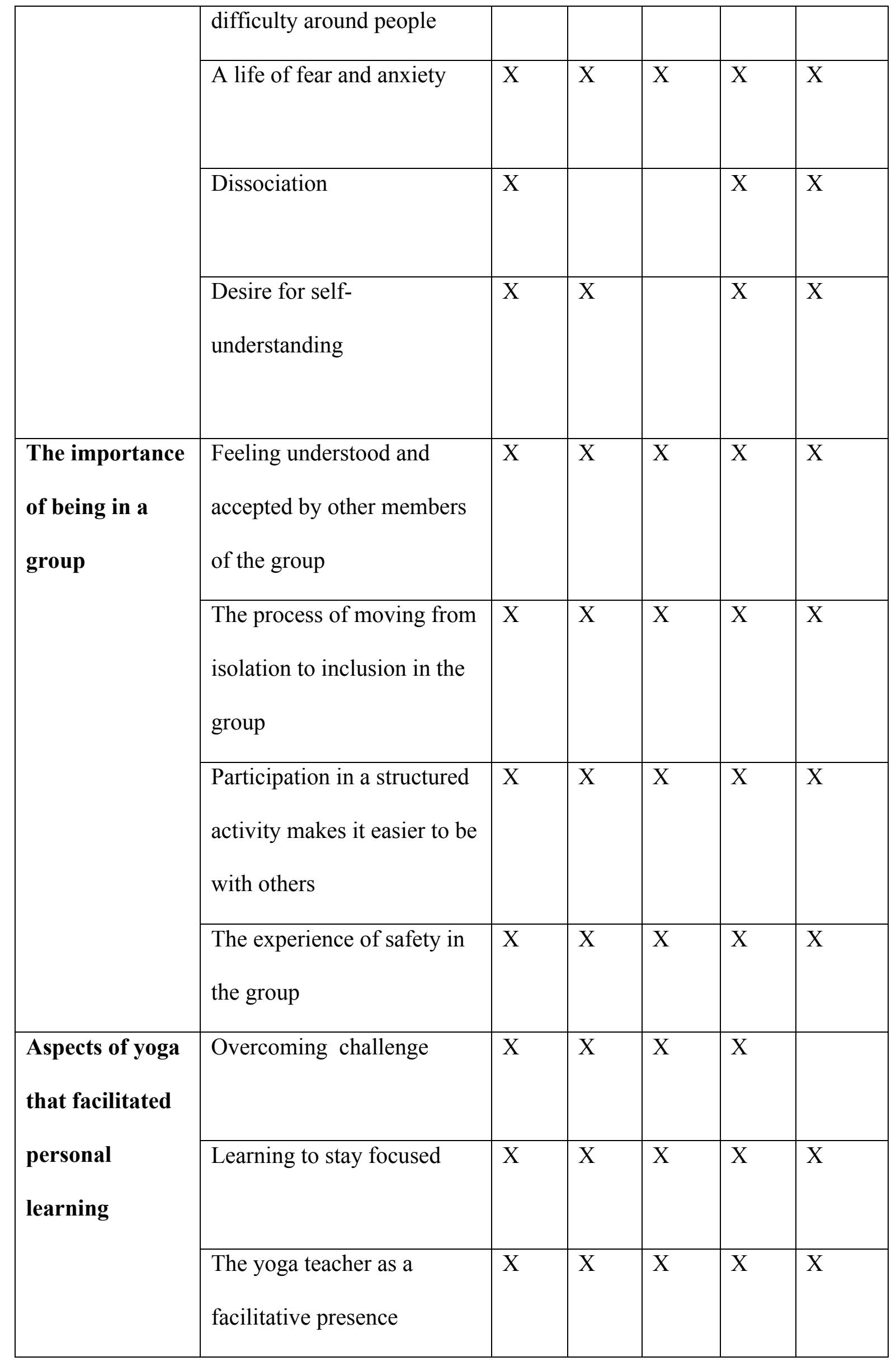




\begin{tabular}{|c|c|c|c|c|c|c|}
\hline $\begin{array}{l}\text { Changes that } \\
\text { occurred } \\
\text { through doing }\end{array}$ & $\begin{array}{l}\text { Learning how to use } \\
\text { patterns of breathing to } \\
\text { maintain well-being }\end{array}$ & $\mathrm{X}$ & $X$ & $X$ & $X$ & $X$ \\
\hline \multirow[t]{7}{*}{ yoga } & $\begin{array}{l}\text { Self-acceptance and } \\
\text { understanding }\end{array}$ & $\mathrm{X}$ & $\mathrm{X}$ & $\mathrm{X}$ & $\mathrm{X}$ & $\mathrm{X}$ \\
\hline & Relief from anxiety & $\mathrm{X}$ & $\mathrm{X}$ & $\mathrm{X}$ & $\mathrm{X}$ & $\mathrm{X}$ \\
\hline & $\begin{array}{l}\text { Greater physical and } \\
\text { cognitive awareness }\end{array}$ & $\mathrm{X}$ & $\mathrm{X}$ & $\mathrm{X}$ & $\mathrm{X}$ & $\mathrm{X}$ \\
\hline & $\begin{array}{l}\text { Gaining relief from inner } \\
\text { critical dialogue }\end{array}$ & $\mathrm{X}$ & $\mathrm{X}$ & $\mathrm{X}$ & $X$ & \\
\hline & Developing self-control & $\mathrm{X}$ & $\mathrm{X}$ & $\mathrm{X}$ & $\mathrm{X}$ & $\mathrm{X}$ \\
\hline & $\begin{array}{l}\text { Gaining relief from pain and } \\
\text { physical tension }\end{array}$ & $\mathrm{X}$ & $\mathrm{X}$ & $\mathrm{X}$ & $\mathrm{X}$ & $\mathrm{X}$ \\
\hline & $\begin{array}{l}\text { Relief from dissociation } \\
\text { achieved through a growing } \\
\text { mind/body connection }\end{array}$ & $\mathrm{X}$ & & $\mathrm{X}$ & $\mathrm{X}$ & $\mathrm{X}$ \\
\hline $\begin{array}{l}\text { Yoga as a } \\
\text { resource for }\end{array}$ & Yoga as a unique resource & $\mathrm{X}$ & $\mathrm{X}$ & $\mathrm{X}$ & $X$ & $\mathrm{X}$ \\
\hline \multirow[t]{2}{*}{ living } & $\begin{array}{l}\text { The Rape Crisis centre as a } \\
\text { whole as a life-saving } \\
\text { resource }\end{array}$ & $\mathrm{X}$ & $\mathrm{X}$ & $\mathrm{X}$ & $\mathrm{X}$ & $\mathrm{X}$ \\
\hline & Making progress & $\mathrm{X}$ & $\mathrm{X}$ & $\mathrm{X}$ & $\mathrm{X}$ & $\mathrm{X}$ \\
\hline
\end{tabular}


Yoga as an adjunct to trauma-focused counselling: a qualitative study

\begin{tabular}{|l|l|l|l|l|l|l|}
\hline & & & & & & \\
\hline
\end{tabular}

Table 2: IPA analysis: main themes and sub-themes. 